\title{
Using thermal sensitivity analysis to determine the impact of drainage on the hydrochemistry of a tropical peat soil from Malaysia
}

\begin{abstract}
Peat from an area of pristine swamp in Malaysia and from an area of that swamp drained 10 years earlier for agriculture was incubated along a temperature gradient from 0 to $20{ }^{\circ} \mathrm{C}$ to simulate microbial activity through changes in temperature. With increasing temperature, nitrate availability decreased in the pristine peat but increased in the drained peat, suggesting that drainage has altered the principle nitrate transformation process from denitrification to nitrification. Sulfate concentrations in the pristine peat exhibited a greater proportional decrease with increasing temperature than in the drained peat, suggesting that drainage has decreased the influence of sulfate reduction over sulfate availability at this site. With the exception of phosphate, nutrient concentrations in the drained site were significantly greater $(\mathrm{P}<0.05)$ than in the pristine site. Biogeochemical models should consider that drained peatlands may respond very differently to the temperature change predicted by current climate change models.
\end{abstract}

Keyword: Climate change; Drainage; Land use; Nutrient; Tropical peat 